\title{
Easy listening
}

I t's that time of year again-no, not summer (although it does feel a bit warmer, particularly north of the equator), but meeting season, with its (seemingly) never-ending life on the conference circuit. Let's see; you've got clothing, toiletries, passport, iPod, laptop and all those books and journals to read in the airport terminal and on your flight. Hold on, let's reorganize by absolute necessity: laptop, iPod, ... toothbrush (?) ... and all that reading you were saving up. Make sure you leave room for the abstract books you're going to accumulate along the way, and yes, you probably should bring at least one change of clothes. Suddenly, you're three inches shorter and your back is aching.

One simple way to lighten your load is to get rid of all those books. No, I don't mean stop reading, just start listening. With the ever-expanding pod world we live in, people are coming up with more and more things to put into MP3 format, making them just a download (and sometimes a credit-card swipe) away. Check out these suggestions to stay on top of your reading list while cruising weightlessly through the departure gate.

There is, of course, the Nature podcast, which is updated weekly and narrated BBC-style by researchers at the University of Cambridge. Each show highlights news features and articles in the current issue of Nature, often with scientist interviews as well as journalist commentaries. Not to be outdone, Science and AAAS also have a podcast. Updated twice a month, the Science podcast covers articles recently featured in the pages of Science and often provides content that complements special issues appearing in the print version of the journal. Also worth downloading are National Public Radio's Science Friday (http://www.sciencefriday.com/feed/) and ScienceTalk from Scientific American (http://www.sciam.com/podcast/). Science Friday is currently featuring a broadcast marking the 25th anniversary of the first AIDS diagnosis, assessing where we currently stand in the face of this epidemic. All the podcasts offer RSS feeds so that the most recent podcast can be delivered straight to your computer desktop, even when you're on the road.

A couple of long flights or layovers allow plenty of time to download and listen to an audiobook on your favorite scientific topic. The offspring of books on tape (Tape? What's that?), audiobooks can be accessed from a variety of websites, some of which allow you to store what you buy in an online library, often with unlimited downloads later. Science-related audiobooks vary from older classics (Darwin's The Voyage of the Beagle, Tantor Media) to some pretty recent publications (Perfectly Reasonable Deviations from the Beaten Track: Selected Letters of Richard Feynman, Recorded Books).
Other interesting downloadable fare includes Bill Bryson's A Short History of Nearly Everything (Random House Audio). Originally appearing in print a few years ago, A Short History chronicles Bryson's educational voyage to understand, well, nearly everything in the scientific world. Starting from the Big Bang and leading up to life on this planet as we currently perceive it, Bryson, a nonscientist, dives into fields ranging from astronomy and physics to anthropology and paleontology, often bringing expert scientists along on his journey to make science, and ourselves, accessible to the masses. Stephen Hawking's A Briefer History of Time (Random House Audio) offers something a bit more philosophical and intellectually challenging. In the updated edition of his now nearly 20-year-old book, Hawking looks to make the often esoteric topics of relativity and quantum theory easier to understand, while also including recent progress in the exciting exploration of time and space, all in a slightly briefer version than the original ( 4 hours and 21 minutes versus 5 hours and 46 minutes). Equally worth listening to, although along a slightly different vein, is The Fabric of the Cosmos (Random House Audio), by Brian Greene. With a narrative style quite different from Hawking's, Greene explains the highly mathematical physical concepts of string theory using everyday experiences and imagery and, thankfully, no equations.

If the space-time continuum is not on your listening menu, then perhaps The Omnivore's Dilemma (Penguin Audio) should be. Although it doesn't get at where we stand in the universe, it does consider where we stand in the food chain. The most surprising message from this food-oriented examination of how humans interact with the natural world is that, if we are what we eat, most of us are made of corn. From the livestock feed given to the animals we consume (even farmed fish!) to the oil and sweeteners used in the prepared foods we buy, it all comes from the cornfield. Maybe even more interesting is how much energy (meaning oil) is consumed in getting our food to the dinner table, compared with the caloric value we obtain when it finally reaches our mouths. If this doesn't turn your stomach, then maybe hearing about the politics and egos involved in one of the biggest scientific discoveries of our time will. The Genome War (Random House Audio) provides a behind-thescenes look at the key figures involved in the race to sequence the human genome, and most of it is not that pretty. What is fascinating, however, is the science and honest work that went into accomplishing this mammoth task.

The above suggestions are just a small sampling of the seemingly limitless number of podcasts and audiobooks available. So in preparing for your next trip, remember to download and pack light, knowing that you will have hours of listening pleasure ahead of you. 